This item was submitted to Loughborough's Research Repository by the author.

Items in Figshare are protected by copyright, with all rights reserved, unless otherwise indicated.

\title{
The positive association of infant weight gain with adulthood body mass index has strengthened over time in the Fels Longitudinal Study
}

\section{PLEASE CITE THE PUBLISHED VERSION}

https://doi.org/10.1111/ijpo.12271

\section{PUBLISHER}

(c) World Obesity Federation. Published by Wiley

\section{VERSION}

AM (Accepted Manuscript)

\section{PUBLISHER STATEMENT}

This work is made available according to the conditions of the Creative Commons Attribution-NonCommercialNoDerivatives 4.0 International (CC BY-NC-ND 4.0) licence. Full details of this licence are available at: https://creativecommons.org/licenses/by-nc-nd/4.0/

\section{LICENCE}

CC BY-NC-ND 4.0

\section{REPOSITORY RECORD}

Lucas, Kimberly, Philip James, Audrey C. Choh, Miryoung Lee, Stefan A. Czerwinski, Ellen W. Demerath, and Will Johnson. 2019. "The Positive Association of Infant Weight Gain with Adulthood Body Mass Index Has Strengthened over Time in the Fels Longitudinal Study". figshare. https://hdl.handle.net/2134/28104. 
The positive association of infant weight gain with adulthood body mass index has strengthened over time in the Fels Longitudinal Study

Kimberly Lucas ${ }^{1}$, Philip James ${ }^{2}$, Audrey C Choh ${ }^{3}$, Miryoung Lee ${ }^{3}$, Stefan A Czerwinski $^{3}$, Ellen W Demerath ${ }^{4}$, William Johnson ${ }^{5}$

${ }^{1}$ Department of Population Health, London School of Hygiene and Tropical Medicine, UK

${ }^{2}$ MRC Unit, The Gambia and MRC International Nutrition Group, London School of Hygiene and Tropical Medicine, UK

${ }^{3}$ Department of Epidemiology, Human Genetics and Environmental Sciences, The University of Texas Health Science Center at Houston, School of Public Health, USA ${ }^{4}$ Division of Epidemiology and Community Health, School of Public Health, University of Minnesota, USA

${ }^{5}$ School of Sport, Exercise and Health Sciences, Loughborough University, UK

Keywords: infant weight gain, adulthood body mass index, adulthood blood pressure, secular trend, birth cohort study, obesity epidemic

Running title: Infant weight gain and adulthood body mass index

Address correspondence to: William Johnson, School of Sport, Exercise and Health Sciences, Loughborough University, UK, W.O.Johnson@lboro.ac.uk, +44 (0)1509228 057

Abbreviations: Body mass index (BMI), weight-for-length Z-score (WLZ), United States of America (USA), odds ratio (OR), confidence interval (CI), World Health Organization (WHO), weight-for-age Z-score (WAZ), systolic blood pressure (SBP), diastolic blood pressure (DBP), analysis of variance (ANOVA), likelihood ratio test (LRT) 


\section{What is already known about this subject:}

- The distribution of birth weight and its positive relationship with childhood obesity has not changed during the $20^{\text {th }}$ century, according to a large population-based cohort study in Denmark, thereby implicating postnatal growth in the development of the obesity epidemic.

- Rapid infant weight gain is associated with greater obesity risk and adulthood body mass index (BMI), but it is unknown whether or not this association is stronger for individuals born during the obesity epidemic compared to those born earlier in the $20^{\text {th }}$ century.

\section{What this study adds:}

- In the Fels Longitudinal Study, the positive association between infant weight gain and young adulthood BMI was over two times stronger among a cohort born during the obesity epidemic era (1970-1997) compared to cohorts born earlier in the $20^{\text {th }}$ century (1933-1949 and 1950-1969).

- A similar secular trend was found for the association of infant weight gain with adulthood systolic blood pressure, thereby extending the results to another measure of cardio-metabolic disease risk.

- As well as potentially implicating rapid infant weight gain in the development of the obesity epidemic, these results demonstrate how the consequences of rapid infant weight gain are likely to be dependent on context. 


\section{ABSTRACT}

\section{Background}

Infant weight gain is positively related to adulthood body mass index (BMI), but it is unknown whether or not this association is stronger for individuals born during (compared to before) the obesity epidemic.

\section{Objectives}

To examine how the infant weight gain-adulthood BMI association might have changed across successive birth year cohorts spanning most of the $20^{\text {th }}$ century.

\section{Methods}

The sample comprised 346 participants in the Fels Longitudinal Study. Confounderadjusted regression models were used to test the associations of conditional weightfor-length Z-score (WLZ), capturing weight change between ages 0-2 years, with young adulthood BMI and blood pressure, including cohort (1933-1949 (N=137), 1950-1969 ( $\mathrm{N}=108), 1970-1997(\mathrm{~N}=101))$ as an effect modifier.

\section{Results}

Conditional WLZ was positively related to adulthood BMI, but there was significant effect modification by birth year cohort such that the association was over two times stronger in the $1970-1997$ cohort ( $\beta 2.31 ; 95 \%$ confidence interval $1.59,3.03)$ compared to the $1933-1949(0.98 ; 0.31,1.65)$ and $1950-1969(0.87 ; 0.21,1.54)$ cohorts. A similar pattern was found for systolic blood pressure. 


\section{Conclusions}

The infant weight gain-adulthood BMI association was over two times stronger among a cohort born during the obesity epidemic era compared to cohorts born earlier in the $20^{\text {th }}$ century. 


\section{INTRODUCTION}

Obesity in the United States of America (USA) is a major public health concern, with the epidemic having begun in the $1970-80$ 's ${ }^{1}$. Understanding which factors have contributed to the secular increase in obesity prevalence may help inform prevention and intervention efforts at the population level.

Prenatal growth rate, indexed by birth weight, has generally increased during the obesity epidemic ${ }^{2}$, likely due to higher levels of maternal obesity ${ }^{3}$. Given that higher birth weight is positively related to risk of obesity later in life ${ }^{4}$, it is possible that the secular trend toward increasing birth weight may have contributed to the development of the obesity epidemic. Alternatively, birth weight may be implicated if its relationship with obesity risk has strengthened over time. Rugholm et $\mathrm{al}^{5}$ tested these ideas in a large population-based cohort study of approximately 250,000 Danish children born between 1936 and 1983, but found no evidence that an observed secular increase in childhood overweight at ages 6-13 years was explained by changes in the distribution or effect of birth weight. Consequently, the authors proposed that early-postnatal environmental influences, likely to affect infant growth, may be more important.

Consistent observational evidence has found that rapid weight gain during infancy is related to increased risk of overweight and/ or obesity ${ }^{6-9}$. In a meta-analysis of individual-level data on 47,661 participants from 10 cohort studies, for example, Druet et $\mathrm{al}^{9}$ found that each one unit increase in weight Z-score change between birth and age one year incurred a two-fold increased odds of childhood obesity (odds 
ratio $(\mathrm{OR}) 1.97 ; 95 \%$ confidence interval $(95 \% \mathrm{Cl}) 1.83,2.12)$ and a $23 \%$ higher odds of adulthood obesity $(1.23 ; 1.16,1.30)$. Despite the 10 cohort studies covering a wide range of birth years (1931-1994), there was little evidence of heterogeneity in the effect of infant weight gain. While this finding suggests that the relationship of infant weight gain with adulthood body mass index (BMI) has not change over time, it is possible that other between-study differences (e.g., population and age at outcome assessment) may have masked any secular trend.

The aim of the present study was to investigate how the relationship between infant weight gain and adulthood BMI may have changed over the $20^{\text {th }}$ century within a single population measured at the same ages. Evidence of a strengthening association would not only implicate infant weight gain in the development of the obesity epidemic, but also indicate that the projected burden of disease (due to infant weight gain) might be more severe than currently thought based on analyses of historical birth cohorts. This would strengthen the rationale for prevention programs targeting rapid infant weight gain.

Adulthood blood pressure was included as a secondary outcome to evaluate whether or not any findings for BMI extend to another more direct measure of cardiometabolic disease risk. This is a reasonable hypothesis given that obesity is a key risk factor for hypertension.

\section{METHODS}




\section{Sample}

The Fels Longitudinal Study began in 1929 as a study of normative child growth and development and continues today as a study of the early-life antecedents of chronic diseases of aging. Mother-infant dyads living in Yellow Springs and other towns in southwestern Ohio, USA have been enrolled from 1929 onward, with the infants being followed-up across their lives.

Starting with a total cohort of 736 participants with available data that consisted of at least one measurement in infancy and adulthood, 379 were excluded for missing information at either birth or age two years. A further 11 participants were excluded because they were preterm births. Gestational age data was missing for 45 participants; however, they were included in the sample to maximize sample size. The 346 participants included in the final sample were predominantly white, nonHispanic singleton infants (165 female, 180 male) and were born between 1933 and 1997. Compared to the final study sample, the excluded sample did not differ with respect to race composition, first born birth status, sex ratio, and singleton birth status.

All protocols and informed consent documents were approved by the Wright State University Institutional Review Board. Parents provided written consent for their offspring's participation until 18 years of age, and children aged 7-18 years provided their additional assent, after which written consent was obtained in adulthood.

\section{Variables}


Exposure: Weight and recumbent length were measured at birth and age two years using standard techniques. In brief, length was measured to the nearest $0.1 \mathrm{~cm}$, using an infantometer, and weight was measured to the nearest $0.1 \mathrm{~kg}$, using a balance beam or digital scale.

Conditional weight-for-length Z-scores (WLZ) were calculated to represent infant relative weight gain as the primary exposure. The conditional WLZ are the standardized residuals of linear regressions of WLZ at age two years on WLZ at birth using the World Health Organization (WHO) growth standards ${ }^{10}$. The resulting variable represents change in WLZ between birth and age two years, independent of size at birth (i.e., WLZ at birth) and regression to the mean ${ }^{11}$. A conditional weightfor-age Z-score (WAZ) variable was also calculated in the same manner. For descriptive purposes, rapid weight gain variables for WAZ and WLZ were calculated as the difference between Z-score at age two years and Z-score at birth (using the definition of rapid growth as $>+0.67$ change in Z-score ${ }^{7}$ ).

Outcomes: The outcome variables were BMI (weight $(\mathrm{kg}) /$ height $\left.(\mathrm{m})^{2}\right)$ and blood pressure (systolic blood pressure (SBP) and diastolic blood pressure (DBP); mmHg), measured in adulthood at target age closest to 18 years. Weight and height in adulthood were measured using standard techniques. For descriptive purposes, a categorical variable was generated based on BMI category (underweight, normal weight, overweight, and obese) using established cut-points. SBP and DBP measurements were taken with a standard mercury sphygmomanometer while participants were seated and at rest. Triplicate measures were taken, and the mean of the final two measurements were used in all analyses. 
Effect modifiers: To capture distinct environmental and social eras in the USA, birth year was categorized into tertiles: 1933-1949 to represent a depression/ wartime cohort; 1950-1969 to represent a post-war/ baby boomer cohort; and 1970-1997 to represent an obesity epidemic cohort. The birth cohort variable was introduced into models as an effect modifier to assess its influence on the relationship between conditional WLZ and the outcomes.

Covariates: Adjustments were made for available variables known to be associated with both the outcome and exposure (i.e., confounder) or just the outcome (i.e., competing effect). Sex (female vs. male), WLZ at birth, race (non-white vs. white, non-Hispanic), multiple birth (twin or triplet vs. singleton), and birth order (second or higher vs. first) were obtained from birth records. Age of adult outcome assessment and adult stature (for blood pressure outcomes) were obtained from adulthood visit data.

\section{Statistical methods}

Statistical analysis was carried out using Stata (version 14, StataCorp LP, College Station, TX). Data were stratified by birth year cohort for descriptive analysis and differences between birth cohorts were tested using chi-squared tests (categorical variables) and analysis of variance (ANOVA; continuous variables).

Multivariable linear regression was used to evaluate the association between conditional WLZ and each outcome variable, including an interaction term between birth year cohort and conditional WLZ in all models. Likelihood ratio tests (LRT) were 
used to test whether the interaction model explained a greater proportion of outcome variance compared to a model not including an interaction term. First, unadjusted regression models were built testing the conditional WLZ-by-birth year cohort interaction. Then, covariates were added to obtain the fully-adjusted models. Only the fully adjusted models are presented as adjustment did not noticeably affect the beta estimates. Post-estimation commands were used to obtain birth cohort-specific estimates of the association between conditional WLZ and respective outcomes and Wald tests were used to evaluate the differences between these estimates. To examine any effect modification by size at birth, a secondary analysis was used to test a WLZ at birth-by-birth year cohort interaction. Conditional WAZ was also tested as the exposure (adjusting for WAZ at birth) because this is the typical exposure variable in the literature to date.

\section{RESULTS}

Descriptive statistics by birth year cohort are provided in Table 1. Birth weight was higher, but weight at age two years was lower, in the 1970-1997 cohort compared to the 1933-1949 and 1950-1969 cohorts. Therefore, WAZ change from 0-2 years decreased from +0.33 Z-scores in the 1933-1949 cohort and +0.38 Z-scores in the 1950-1969 cohort to -0.26 Z-scores in the 1970-1997 cohort. Adulthood BMI was highest in the most recently born cohort, resulting in obesity prevalence being higher in the 1970-1997 cohort (16.8\%) compared to the $1933-1949$ cohort $(2.2 \%)$ and the 1950-1969 cohort (1.9\%). 
The results showed that the association between conditional WLZ and adulthood BMI was the strongest amongst the most recent birth cohort of participants born between 1970-1997. In fully-adjusted regression models (Table 2), the interaction term for the 1970-1997 cohort was significant $(\beta$ 1.33; $95 \% \mathrm{Cl} 0.35,2.32)$, indicating that the effect of infant weight gain was higher in the most recent cohort compared to the 1933-1949 (referent) cohort. The LRT comparing this model to a model without the birth year cohort-by-WLZ interaction terms provided strong evidence that accounting for effect modification significantly improved model fit $(p=0.005)$. The cohort-specific estimates for each birth year cohort are visually represented in Figure 1. Conditional WLZ was associated with increased adulthood BMI in all three birth cohorts; however, effect size was more than doubled in the 1970-1997 cohort, compared to the 1950-1969 and 1933-1949 cohorts ( $\beta 2.31$ versus 0.87 and 0.98; $p$ $=0.004$ and 0.008 , respectively)

Results for SBP indicate that the effect of conditional WLZ was higher in the 19501969 cohort compared to the 1933-1949 cohort (Table 2), with an interaction term estimate of $2.58(95 \% \mathrm{Cl} 0.25,4.92)$. Similar effect modification $(2.18 ;-0.23,4.60)$ was observed for the 1970-1997 cohort at alpha 10\%. The LRT also indicated evidence for a better fit of the interaction model at alpha $10 \%(p=0.063)$. Cohortspecific estimates (Figure 1) show approximately doubled effect sizes in the 19501969 and 1970-1997 cohorts, compared to the 1933-1949 cohort ( $\beta 2.26$ and 1.85 versus $-0.33 ; p=0.030$ and 0.077 , respectively).

For DBP, there was no evidence to suggest effect modification (Table 2) and the LRT showed no evidence of an improved model fit with interaction terms $(p=0.421)$. 
A secondary analysis testing a WLZ at birth-by-birth year cohort interaction indicated no evidence of effect modification by size at birth. Replacing the exposure with conditional WAZ also produced the same pattern of results across outcomes.

\section{DISCUSSION}

Early research on the developmental origins of obesity and adiposity-related diseases focused on the influence of birth weight, and later infant growth, in birth cohorts from the early- and mid-20 ${ }^{\text {th }}$ century ${ }^{12-14}$, before the onset of the obesity epidemic and at a time when maternal and infant nutrition (among other factors) were far different than today ${ }^{15}$. While subsequent research has replicated some of these findings in more recently born cohorts, there is a dearth of knowledge on how these associations might have changed over time. This knowledge is important not only because it points towards the factors underlying the development of the obesity epidemic, thereby informing prevention and intervention efforts at the population level, but also because it demonstrates how the consequences of some disease risk factor might be dependent on context. The present study focused on infant weight gain, a key risk factor for obesity ${ }^{6-9}$, and found that a positive relationship with young adulthood BMI was over two times stronger among a cohort born during the obesity epidemic era (1970-1997) compared to cohorts born earlier in the $20^{\text {th }}$ century (19331949 and 1950-1969). A similar secular trend was found for the association of infant weight gain with adulthood systolic blood pressure, thereby extending the results to another measure of cardio-metabolic disease risk. These findings provide novel evidence that the adverse sequelae of rapid infant weight gain may be more 
pronounced than might have been previously thought, based on analyses of birth cohorts not born into the obesity epidemic.

The association of rapid infant weight gain (and infant BMI) with adulthood BMI has been previously established within the Fels Longitudinal Study cohort ${ }^{16,17}$, and the current study findings are in agreement with the larger body of systematic reviews and meta-analyses ${ }^{6-9}$. Unlike one meta-analysis ${ }^{9}$ which did not find evidence of heterogeneity between studies born at different points during the $20^{\text {th }}$ century, however, we found clear evidence that the association of infant weight gain with adulthood BMI strengthened over time. This discrepancy may be because the cohorts included in the meta-analysis were from different populations with childhood and adulthood outcomes at a range of ages (e.g., adulthood ages 17-66 years), which has the potential to mask any underlying secular trend. Conversely, the Fels Longitudinal Study is somewhat unique in its sequential birth cohort design which allows for investigation (within a single population) of shifts over a wide range of birth years in longitudinal processes and relationships spanning birth to adulthood. One large population-based cohort study in Denmark had the available data to ask the same research question for birth weight but, similar to our secondary analysis, found no evidence of a strengthening relationship with obesity risk over time ${ }^{5}$. Both studies, therefore, provide evidence that environmental influences contributing to the obesity epidemic likely operate via accelerated postnatal not prenatal growth.

Despite adulthood obesity prevalence being approximately eight times higher in the obesity epidemic cohort (1970-1997) compared to the depression/ wartime (19331949) and post-war/ baby boomer (1950-1969) cohorts, and infant weight gain being 
positively related to obesity risk, average infant weight gain (unconditional of length) was actually lowest in the most recently born cohort. This finding is in agreement with previous Fels Longitudinal Study publications showing a secular trend in the $20^{\text {th }}$ century toward slower infant weight gain and lower infant BMI peak ${ }^{18,19}$, as well as similar evidence from the United Kingdom and other European studies ${ }^{20,21}$. A strengthening association of infant weight gain with adulthood BMI over time, as documented in the present paper, provides one explanation for counterintuitive reports of increasing adulthood BMI and decreasing infant weight gain, despite these two variables being positively related.

In addition to changes in infant growth, maternal factors have changed over the study period, and it is likely that these contributed to the strengthening infant weight gain-adulthood BMI association. For example, an overall increase in maternal BMI has been documented in the USA ${ }^{3}$ and, specifically in the Fels Longitudinal Study, the prevalence of maternal overweight or obesity increased from 18\% in 1930-1949 to $48 \%$ in $1990-2008^{18}$. Because maternal obesity is related to offspring obesity ${ }^{22}$, adjusting for maternal BMI in the present analysis may have attenuated the effect size for the most recently born cohort and made it more comparable to the effect sizes for the other two cohorts. Alternatively, emerging evidence suggests that offspring of overweight and obese mothers may have decelerated infant growth ${ }^{23}$, in agreement with the concurrent secular trends toward higher maternal BMI and slower infant weight gain discussed in the previous paragraph ${ }^{18-21}$, perhaps due to altered hormone levels in breastmilk suppressing appetite and/ or growth ${ }^{24}$. In this scenario, adjustment for maternal BMI may have accentuated (as opposed to attenuated) the effect size for the most recently born cohort. As another related 
example, breastfeeding is associated with slower infant growth and decreased risk of overweight and obesity ${ }^{25}$. Therefore, a secular trend toward lower breast feeding rates in our sample, which is possible given evidence from other studies ${ }^{26}$, and overweight and obese women being less likely to successfully breastfeed compared to normal weight women ${ }^{27}$, may have contributed to the strengthening infant weight gain-adulthood BMI association. Unfortunately, maternal BMI and infant feeding are not complete within the Fels Longitudinal Study dataset and therefore were not included in order to maximize the sample size.

Less clear evidence of a secular trend in the effect of infant weight gain was observed for blood pressure outcomes. This may be because infant weight gain is a less important determinant of adulthood blood pressure than $\mathrm{BMI}^{28}$, with most evidence demonstrating stronger associations of blood pressure with childhood growth than infant growth per $\mathrm{se}^{29}$. Also, secular trends in blood pressure are not as clear cut as those for obesity and do not follow the same time course, at least in the Fels Longitudinal Study ${ }^{30}$. Nonetheless, tentative evidence was found for SBP, thereby extending the results to another measure of cardio-metabolic disease risk.

The Fels Longitudinal Study is unique in that it has assessed growth from birth to adulthood in participants born from 1929 onward. This is a key strength as it allows longitudinal associations and processes to be modelled over changing social and environmental circumstances. In terms of limitations, participants are from a homogenous, European-ancestry population in a high-income country, which limits generalizability to other populations. In addition, extensive covariate adjustment was not possible. Despite adjusting for birth weight, greater infant weight gain may be 
less deleterious in the older cohorts because it is more likely to represent a normal biological response to in utero growth constraint (which we would expect to be more common in the older cohorts). Unfortunately, with our limited sample size it was not prudent to test this hypothesis by stratifying analyses on birth weight. Although body composition data are available in the Fels Longitudinal Study, methods have changed over time, which constrains comparisons across different birth year cohorts. Therefore, interpreting the current findings in terms of adiposity and cardiovascular risk is challenging, as BMI includes both fat and fat-free mass components. Larger scale studies with more direct cardio-metabolic disease risk marker outcomes, and covariate information on maternal factors, are required.

In conclusion, in the Fels Longitudinal Study, the positive association between infant weight gain and young adulthood BMI was over two times stronger among a cohort born during the obesity epidemic era (1970-1997) compared to cohorts born earlier in the $20^{\text {th }}$ century (1933-1949 and $\left.1950-1969\right)$. As well as potentially implicating rapid infant weight gain in the development of the obesity epidemic, these results demonstrate how the consequences of rapid infant weight gain are likely to be dependent on context. 


\section{CONFLICTS OF INTEREST STATEMENT}

All authors have no conflicts of interest to disclose.

\section{ACKNOWLEDGEMENTS}

We wish to thank the staff at the Lifespan Health Research Centre, Boonshoft School of Medicine, Wright State University for their commitment to data collection over the years and for preparing the dataset. We also wish to thank the Fels Longitudinal Study participants for their long-term commitment to the study without which this paper would not have been possible.

WJ acknowledges support from the National Institute for Health Research (NIHR) Leicester Biomedical Research Centre, which is a partnership between University Hospitals of Leicester NHS Trust, Loughborough University, and the University of Leicester.

WJ, KL, and EWD conceptualized the study. KL carried out the analyses and drafted the initial manuscript. SAC, EWD, ACC, and ML collected the data. ACC created the dataset and conducted preliminary analyses. $\mathrm{KL}, \mathrm{PJ}, \mathrm{ACC}, \mathrm{ML}, \mathrm{SAC}, \mathrm{EWD}$, and WJ made substantial contributions to the interpretation of the data, revised the manuscript critically for important intellectual content, gave final approval of the version to be published, and agree to be accountable for all aspects of the work. 


\section{REFERENCES}

1. Ogden CL, Carroll MD, Fryar CD, Flegal KM. Prevalence of Obesity Among Adults and Youth: United States, 2011-2014. NCHS Data Brief. 2015(219):1-8.

2. Oken E. Secular trends in birthweight. Nestle Nutr Inst Workshop Ser. 2013;71:103-114.

3. Galtier-Dereure F, Boegner C, Bringer J. Obesity and pregnancy: complications and cost. Am J Clin Nutr. 2000;71(5 Suppl):1242S-1248S.

4. Yu ZB, Han SP, Zhu GZ, et al. Birth weight and subsequent risk of obesity: a systematic review and meta-analysis. Obes Rev. 2011;12(7):525-542.

5. Rugholm S, Baker JL, Olsen LW, Schack-Nielsen L, Bua J, Sørensen TI. Stability of the association between birth weight and childhood overweight during the development of the obesity epidemic. Obesity Research. 2005;13(12):2187-2194.

6. Monteiro POA, Victora C. Rapid growth in infancy and childhood and obesity in later life-a systematic review. Obesity reviews. 2005;6(2):143-154.

7. Ong KK, Loos RJ. Rapid infancy weight gain and subsequent obesity: systematic reviews and hopeful suggestions. Acta Paediatr. 2006;95(8):904-908. 8. Baird J, Fisher D, Lucas P, Kleijnen J, Roberts H, Law C. Being big or growing fast: systematic review of size and growth in infancy and later obesity. BMJ. $2005 ; 331(7522): 929$.

9. Druet C, Stettler N, Sharp S, et al. Prediction of childhood obesity by infancy weight gain: an individual-level meta-analysis. Paediatr Perinat Epidemiol. 2012;26(1):19-26. 
10. de Onis M, Garza C, Victora CG, Onyango AW, Frongillo EA, Martines J. The WHO Multicentre Growth Reference Study: planning, study design, and methodology. Food and nutrition bulletin. 2004;25(1 suppl1):S15-S26.

11. Keijzer-Veen MG, Euser AM, van Montfoort N, Dekker FW, Vandenbroucke JP, Van Houwelingen HC. A regression model with unexplained residuals was preferred in the analysis of the fetal origins of adult diseases hypothesis. J Clin Epidemiol. 2005;58(12):1320-1324.

12. Barker DJ, Osmond C, Golding J, Kuh D, Wadsworth ME. Growth in utero, blood pressure in childhood and adult life, and mortality from cardiovascular disease. BMJ. 1989;298(6673):564-567.

13. Curhan GC, Chertow GM, Willett WC, et al. Birth weight and adult hypertension and obesity in women. Circulation. 1996;94(6):1310-1315.

14. Eriksson JG, Forsén T, Tuomilehto J, Winter PD, Osmond C, Barker DJ. Catch-up growth in childhood and death from coronary heart disease: longitudinal study. BMJ. 1999;318(7181):427-431.

15. Popkin BM. The nutrition transition: an overview of world patterns of change. Nutr Rev. 2004;62(7 Pt 2):S140-143.

16. Demerath EW, Reed D, Choh AC, et al. Rapid postnatal weight gain and visceral adiposity in adulthood: the Fels Longitudinal Study. Obesity (Silver Spring). 2009;17(11):2060-2066.

17. Johnson W, Choh AC, Lee M, et al. Is infant body mass index associated with adulthood body composition trajectories? An exploratory analysis. Pediatr Obes. 2017;12(1):10-18. 
18. Johnson W, Choh AC, Soloway LE, Czerwinski SA, Towne B, Demerath EW. Eighty-year trends in infant weight and length growth: the Fels Longitudinal Study. J Pediatr. 2012;160(5):762-768.

19. Johnson W, Choh AC, Lee M, Towne B, Czerwinski SA, Demerath EW. Characterization of the infant BMI peak: sex differences, birth year cohort effects, association with concurrent adiposity, and heritability. Am J Hum Biol. 2013;25(3):378-388.

20. Deheeger M, Rolland-Cachera MF. Longitudinal study of anthropometric measurements in Parisian children aged ten months to 18 years. Arch Pediatr. 2004;11(9):1139-1144.

21. Johnson W, Li L, Kuh D, Hardy R. How Has the Age-Related Process of Overweight or Obesity Development Changed over Time? Co-ordinated Analyses of Individual Participant Data from Five United Kingdom Birth Cohorts. PLoS Med. 2015;12(5):e1001828; discussion e1001828.

22. Yu Z, Han S, Zhu J, Sun X, Ji C, Guo X. Pre-pregnancy body mass index in relation to infant birth weight and offspring overweight/obesity: a systematic review and meta-analysis. PLoS One. 2013;8(4):e61627.

23. Ode KL, Gray HL, Ramel SE, Georgieff MK, Demerath EW. Decelerated early growth in infants of overweight and obese mothers. J Pediatr. 2012;161(6):10281034.

24. Fields DA, George B, Williams M, et al. Associations between human breast milk hormones and adipocytokines and infant growth and body composition in the first 6 months of life. Pediatr Obes. 2017. 
25. Betoko A, Lioret S, Heude B, et al. Influence of infant feeding patterns over the first year of life on growth from birth to 5 years. Pediatr Obes. 2017;12(Suppl 1):94-101.

26. Fomon S. Infant feeding in the 20th century: formula and beikost. $J$ Nutr. 2001;131(2):409S-420S.

27. Turcksin R, Bel S, Galjaard S, Devlieger R. Maternal obesity and breastfeeding intention, initiation, intensity and duration: a systematic review. Matern Child Nutr. 2014;10(2):166-183.

28. Huxley RR, Shiell AW, Law CM. The role of size at birth and postnatal catchup growth in determining systolic blood pressure: a systematic review of the literature. J Hypertens. 2000;18(7):815-831.

29. Law C, Shiell A, Newsome C, et al. Fetal, infant, and childhood growth and adult blood pressure a longitudinal study from birth to 22 years of age. Circulation. 2002;105(9):1088-1092.

30. Choh AC, Nahhas RW, Lee M, et al. Secular trends in blood pressure during early-to-middle adulthood: the Fels Longitudinal Study. J Hypertens. 2011;29(5):838845. 


\section{FIGURE LEGENDS}

Figure 1. Associations (with 95\% Cls) of conditional WLZ at age two years with adulthood BMI, SBP, and DBP for each birth year cohort, estimated from general linear regression models (Table 2)

P-values for differences between the estimates are from Wald tests.

Cls, confidence interval; BMI, body mass index; SBP, systolic blood pressure; DBP, diastolic blood pressure; WLZ, weight-for-length Z-score 
Table 1: Descriptive statistics of the study sample in infancy and adulthood, by birth year cohort

\begin{tabular}{|c|c|c|c|c|c|c|}
\hline & & \multicolumn{3}{|c|}{ Birth year cohort } & \multirow[b]{2}{*}{$p$-value ${ }^{1}$} & \multirow[b]{2}{*}{$\begin{array}{c}\text { Total } \\
(\mathrm{N}=346)\end{array}$} \\
\hline & & $\begin{array}{c}1933-1949 \\
(N=137)\end{array}$ & $\begin{array}{c}1950-1969 \\
(N=108)\end{array}$ & $\begin{array}{c}1970-1997 \\
(N=101)\end{array}$ & & \\
\hline Female & $\%(n)$ & $46.7(64)$ & $50.0(54)$ & $46.5(47)$ & 0.845 & $47.7(165)$ \\
\hline White, non-Hispanic & $\%(n)$ & $100.0(137)$ & $98.2(106)$ & $95.1(96)$ & 0.027 & $98.0(339)$ \\
\hline Firstborn & $\%(n)$ & $29.2(40)$ & $25.9(28)$ & $39.6(40)$ & 0.083 & $31.2(108)$ \\
\hline Singleton birth & $\%(n)$ & $98.5(135)$ & $95.4(103)$ & $94.1(95)$ & 0.169 & $96.2(333)$ \\
\hline Gestational age (wk) ( $N=45$ missing $)$ & Mean (SD) & $40.0(1.34)$ & $39.9(1.37)$ & $39.7(1.29)$ & 0.266 & $39.9(1.34)$ \\
\hline \multicolumn{7}{|l|}{ Birth measures } \\
\hline Weight (kg) & Mean (SD) & $3.33(0.46)^{a}$ & $3.33(0.44)^{b}$ & $3.51(0.49)^{\mathrm{ab}}$ & 0.007 & $3.38(0.47)$ \\
\hline Length (cm) & Mean (SD) & $50.01(1.99)^{a}$ & $49.83(2.24)^{\mathrm{b}}$ & $51.85(2.75)^{\mathrm{ab}}$ & $<0.001$ & $50.49(2.49)$ \\
\hline WAZ2 & Mean (SD) & $0.04(0.96)^{\mathrm{a}}$ & $0.06(0.95)^{b}$ & $0.39(0.99)^{a b}$ & 0.010 & $0.15(0.97)$ \\
\hline LAZ & Mean (SD) & $0.25(1.03)^{a}$ & $0.17(1.23)^{b}$ & $1.22(1.42)^{\mathrm{ab}}$ & $<0.001$ & $0.51(1.30)$ \\
\hline WLZ & Mean (SD) & $-0.17(1.00)$ & $-0.06(1.45)$ & $-0.89(1.20)$ & $<0.001$ & $-0.35(1.27)$ \\
\hline \multicolumn{7}{|l|}{2 year measures } \\
\hline Weight (kg) & Mean (SD) & $12.43(1.25)$ & $12.52(1.30)^{\mathrm{a}}$ & $12.12(1.47)^{\mathrm{a}}$ & 0.077 & $12.37(1.34)$ \\
\hline Length (cm) & Mean (SD) & $87.10(2.77)$ & $87.84(2.87)^{\mathrm{a}}$ & $86.37(3.33)^{a}$ & 0.002 & $87.12(3.02)$ \\
\hline WAZ & Mean (SD) & $0.37(0.80)^{\mathrm{a}}$ & $0.44(0.86)^{\mathrm{b}}$ & $0.13(0.96)^{\mathrm{ab}}$ & 0.030 & $0.32(0.87)$ \\
\hline LAZ & Mean (SD) & $0.09(0.87)$ & $0.32(0.90)^{a}$ & $-0.10(1.06)^{\mathrm{a}}$ & 0.006 & $0.11(0.95)$ \\
\hline WLZ & Mean (SD) & $0.40(0.82)^{a}$ & $0.32(0.91)^{b}$ & $0.22(0.88)^{a b}$ & 0.288 & $0.32(0.87)$ \\
\hline WAZ change $0-2$ years & Mean (SD) & $0.33(1.08)^{\mathrm{a}}$ & $0.38(1.04)^{b}$ & $-0.26(1.19)^{a b}$ & $<0.001$ & $0.18(1.13)$ \\
\hline LAZ change $0-2$ years & Mean (SD) & $-0.16(1.04)^{a}$ & $0.15(1.21)^{b}$ & $-1.33(1.49)^{a b}$ & $<0.001$ & $-0.40(1.37)$ \\
\hline WLZ change $0-2$ years & Mean (SD) & $0.57(1.12)^{\mathrm{a}}$ & $0.38(1.60)^{b}$ & $1.10(1.41)^{\mathrm{ab}}$ & $<0.001$ & $0.67(1.40)$ \\
\hline Age of outcome assessment & Median (IQR) & $20.0(18.1,20.2)^{\mathrm{ab}}$ & $19.9(18.0,20.1)^{\mathrm{a}}$ & $18.6(18.2,19.8)^{b}$ & $<0.001$ & $19.7(18.1,20.1)$ \\
\hline Adult weight $(\mathrm{kg})$ & Mean (SD) & $66.62(12.93)^{\mathrm{a}}$ & $66.22(12.14)^{b}$ & $72.53(18.30)^{a b}$ & 0.002 & $68.22(14.71)$ \\
\hline Adult stature (cm) & Mean (SD) & $173.59(8.92)$ & $171.99(9.29)$ & $172.28(9.91)$ & 0.356 & $172.71(9.34)$ \\
\hline Adult BMI (kg/m²) & Median (IQR) & $21.7(19.7,23.6)^{a}$ & $21.6(20.3,24.1)^{b}$ & $22.7(20.6,27.1)^{\mathrm{ab}}$ & $<0.001$ & $21.8(20.2,24.2)$ \\
\hline \multicolumn{7}{|l|}{ Adult BMI $\left(\mathrm{kg} / \mathrm{m}^{2}\right)$ category } \\
\hline Underweight $(<18.5)$ & $\%(n)$ & $12.4(17)$ & $5.6(6)$ & $5.9(6)$ & $<0.001$ & $8.4(29)$ \\
\hline
\end{tabular}




\begin{tabular}{|c|c|c|c|c|c|c|}
\hline Normal (18.5-24.9) & $\%(n)$ & $73.7(101)$ & $76.9(83)$ & $62.4(63)$ & & $71.4(247)$ \\
\hline Overweight (25-29.9) & $\%(\mathrm{n})$ & $11.7(16)$ & $15.7(17)$ & $14.9(15)$ & & $13.9(48)$ \\
\hline Obese $(\geq 30)$ & $\%(n)$ & $2.2(3)$ & $1.9(2)$ & $16.8(17)$ & & $6.4(22)$ \\
\hline $\mathrm{SBP}(\mathrm{mmHg})(\mathrm{N}=2$ missing $)$ & Mean (SD) & $106.61(10.80)$ & 107.69 (10.99) & $108.37(9.36)$ & 0.431 & $107.47(10.46)$ \\
\hline $\mathrm{DBP}(\mathrm{mmHg})(\mathrm{N}=2$ missing $)$ & Mean (SD) & $68.13(7.36)^{\mathrm{a}}$ & $64.37(9.20)^{\mathrm{ab}}$ & $67.28(9.08)^{\mathrm{b}}$ & 0.002 & $66.70(8.61)$ \\
\hline
\end{tabular}

DBP $(\mathrm{mmHg})(\mathrm{N}=2 \mathrm{missing})$

Mean (SD)

$68.13(7.36)$

$64.37(9.20)^{\mathrm{ab}}$

$67.28(9.08)^{\mathrm{b}}$

0.002

$66.70(8.61)$

score; LAZ, length-for-age Z-score; WLZ, weight-for-length Z-score

${ }^{1}$ Birth cohort differences tested using chi-squared tests for categorical variables and ANOVA (with Bonferroni correction) for continuous variables; alphabetic superscripts indicate a difference between cohorts (with same superscript) at $p<0.05$

2Z-scores calculated using the 2006 WHO growth standards 
Table 2: Regression models ${ }^{1}$ testing the association of conditional WLZ ${ }^{2}$ with adulthood BMI, SBP, and DBP and for effect modification by birth year cohort

\begin{tabular}{|c|c|c|c|c|c|c|c|c|c|}
\hline & \multicolumn{3}{|c|}{ BMI $\left(\mathrm{kg} / \mathrm{m}^{2}\right)(\mathrm{N}=346)$} & \multicolumn{3}{|c|}{$\operatorname{SBP}(\mathrm{mmHg})(\mathrm{N}=344)$} & \multicolumn{3}{|c|}{$\mathrm{DBP}(\mathrm{mmHg})(\mathrm{N}=344)$} \\
\hline & Estimate & $95 \% \mathrm{Cl}$ & $p$ & Estimate & $95 \% \mathrm{Cl}$ & $p$ & Estimate & $95 \% \mathrm{Cl}$ & $p$ \\
\hline Constant & 22.00 & $21.03,22.98$ & $<0.001$ & 108.95 & $106.34,111.56$ & $<0.001$ & 69.45 & $67.04,71.86$ & $<0.001$ \\
\hline Conditional WLZ & 0.98 & $0.31,1.65$ & 0.004 & -0.33 & $-2.00,1.35$ & 0.701 & 0.63 & $-0.91,2.18$ & 0.422 \\
\hline \multicolumn{10}{|l|}{ Birth year cohort } \\
\hline 1933-1949 (referent) & - & - & - & - & - & - & - & - & - \\
\hline 1950-1969 & 0.68 & $-0.26,1.63$ & 0.155 & 2.06 & $-0.26,4.38$ & 0.082 & -3.20 & $-5.34,-1.06$ & 0.003 \\
\hline 1970-1997 & 3.07 & $2.05,4.08$ & $<0.001$ & 3.18 & $0.68,5.68$ & 0.013 & 0.21 & $-2.10,2.51$ & 0.861 \\
\hline \multicolumn{10}{|l|}{$\begin{array}{l}\text { Conditional WLZ-by-birth } \\
\text { year cohort }\end{array}$} \\
\hline 1933-1949 (referent) & - & - & - & - & - & - & - & - & - \\
\hline 1950-1969 & -0.11 & $-1.05,0.84$ & 0.827 & 2.58 & $0.25,4.92$ & 0.030 & -0.04 & $-2.19,2.12$ & 0.972 \\
\hline 1970-1997 & 1.33 & $0.35,2.32$ & 0.008 & 2.18 & $-0.23,4.60$ & 0.077 & 1.25 & $-0.98,3.48$ & 0.272 \\
\hline \multicolumn{10}{|l|}{ Sex } \\
\hline Male (referent) & - & - & - & - & - & - & - & - & - \\
\hline Female & -0.54 & $-1.33,0.25$ & 0.177 & -6.84 & $-9.75,-3.93$ & $<0.001$ & -2.71 & $-5.40,-0.03$ & 0.047 \\
\hline WLZ at birth & 0.24 & $-0.08,0.57$ & 0.144 & 0.20 & $-0.61,1.01$ & 0.630 & 0.39 & $-0.36,1.13$ & 0.311 \\
\hline Age of outcome assessment & 0.28 & $0.12,0.44$ & 0.001 & 0.68 & $0.30,1.07$ & 0.001 & 0.59 & $0.24,0.95$ & 0.001 \\
\hline Adult stature & - & - & - & 0.17 & $0.01,0.32$ & 0.038 & -0.01 & $-0.15,0.14$ & 0.919 \\
\hline $\mathrm{R}^{2}$ & 0.24 & & & 0.29 & & & 0.11 & & \\
\hline
\end{tabular}

BMI, body mass index; SBP, systolic blood pressure; DBP, diastolic blood pressure; WLZ, weight-for-length Z-score

${ }^{1}$ In addition to the focal variables shown, these models were also adjusted for birth order (second or higher vs. first), multiple birth (twin or triplet vs. singleton), and race (non-white vs. white)

${ }^{2}$ Conditional WLZ calculated as the standardized residuals from linear regressions of Z-score at age two years on Z-score at birth; Z-scores calculated using the 2006 WHO growth standards 